\title{
Direito Sanitário, Ministério Público e Reforma Psiquiátrica
}

\author{
HEALTH LAW, PUBLIC PROSECUTION SERVICE AND \\ THE PSYCHIATRIC REFORMATION
}

Renoir da Silva Cunha ${ }^{(*)}$

\section{RESUMO}

Fazendo uma reconstituição histórica, chama a atenção para o tratamento manicomial como forma de exclusão do doente e para a mercantilização da psiquiatria, com o grande aumento de leitos em hospitais psiquiátricos. Aponta para o importante papel do Ministério Público na reorientação do modelo assistencial ao doente psiquiátrico enquanto fiscalizador dos serviços de relevância pública e defensor dos interesses da sociedade, colocando em pauta o movimento antimanicomial trazido pela Lei de Reforma Psiquiátrica, suscitando maior debate sobre a exeqüibilidade, aplicabilidade e efetividade da mesma, visando além do acesso a tratamento de qualidade, à humanização e ao resgate da dignidade e cidadania do paciente.

\section{Descritores}

Reforma Psiquiátrica; Luta antimanicomial; Direitos humanos; Leitos hospitalares; Exclusão.

\section{ABSTRACT}

Doing one historic reconstitution, call the attention for its manicomial treatment as a form of exclusion of the ill and for the mercantilization of the psychiatry, with the ample augmentation of beds into psychiatric hospitals.

(*) Membro do Ministério Público do Estado do Rio Grande do Sul em monografia apresentada em curso de Especialização à Distância em Direito Sanitário para Membros do Ministério Público e da Magistratura Estadual, realizado pela UNB. E-mail: cidadania@mp.rs.gov.br. Entrada: 2.7.2003 - Aprovado em 11.9.2003. 
Appoints for the important paper of the Public Ministry at the reorientation of the assistencial model to the ill psychiatric while fiscalizator of the services of public relevance and defensor of the interests from the society, by setting in rule the antimanicomial movement carried for the law as of Psychiatric Reform, exciting greater discussion above the feasibility, applicability and effectivity from the same, looking at beyond of the access to treatment of quality, the humanization and the rescue from the dignity and citizenship from the patient.

\section{Keywords}

Psychiatric reform; fight antimanicomial; human rights; Hospital stream beds; Exclusion.

\section{INTRODUÇÃO}

O escopo destas reflexões de Direito Sanitário, sobre a Reforma Psiquiátrica e o Ministério Público, consiste na visão crítica da "Reorientação do Modelo Assistencial" de Saúde Mental na perspectiva do Ministério Público, enquanto órgão fiscalizador dos serviços de relevância pública e defensor dos interesses da sociedade. Destarte, a pretensão é a de enfrentar a atual polêmica sobre Reforma Psiquiátrica e, notadamente, do movimento denominado luta antimanicomial, buscando demonstrar que o resgate da cidadania das pessoas portadoras de sofrimento mental não se esgota com o fechamento, puro e simples, dos manicômios. Não desconhecendo que tal instituição, manicomial, é lugar de exclusão e desrespeito aos direitos humanos, afirmamos não ser ela o paradigma a ser superado para que se veja o doente mental como sujeito de direitos e, portanto, cidadão. Sendo assim, há que se transpor o paradigma da exclusão e da segregação, que culturalmente, está solidificado na família, na sociedade e no Estado, espelhando-se na legislação dos últimos dois séculos e, buscando uma sociedade pluralista, justa e solidária; laborar para o desenvolvimento de uma rede de atenção que privilegie as potencialidades do doente, aceite suas limitações e the assegure o direito a uma existência digna. Nesse diapasão, pretendemos enfrentar, ainda que de modo a suscitar o debate crítico do tema, mais do que apresentar posicionamento pronto e acabado, a própria exeqüibilidade, aplicabilidade e especialmente efetividade da Lei de Reforma Psiquiátrica, a fim de que o avanço da linha antimanicomial não implique no retrocesso da qualidade, humanização, acesso e controle social, indicativo de sua organicidade para com a construção de um Sistema Único de Saúde, público, de amplo acesso, eficaz, cidadão e com controle social.

Almejamos, dessarte, esboçar visão crítica da "Reorientação do Modelo Assistencial" de Saúde Mental na perspectiva do Ministério Público, enquanto órgão fiscalizador dos serviços de relevância pública e defensor dos 
interesses da sociedade, sem a pretensão de esgotar o tema em três dezenas de páginas, senão evidenciar visão crítica e ampla sobre os posicionamentos que se alinharam nas últimas décadas na busca por uma mudança de postura no enfrentamento da questão, ruptura com o paradigma anterior e fomento do debate de opções que possam, ainda que não solucionem o problema, indicar alternativas de melhoria da qualidade de vida de quem sofre.

Faz-se mister, para tanto, a identificação do verdadeiro paradigma a ser transposto, o que se fará na primeira parte deste ensaio, reconstituindo a trajetória do manicômio como lugar de exclusão, desde o seu nascimento até os dias de hoje, e apontando a mercantilização do sofrimento psíquico com a identificação de quem são os verdadeiros clientes do manicômio.

$\mathrm{Na}$ segunda parte, discorreremos sobre as tentativas de transposição da exclusão, alinhando idéias e conceitos que permitam remover os rótulos impostos ao portador de sofrimento mental, apontando as possibilidades de inserção social de quem sofre e as dificuldades de implementação dos textos legislativos Estadual e Federal que se propuseram a equacionar o problema.

Nas considerações finais, menos concluindo e mais suscitando maior debate e enfrentamento das complexas questões que envolvem a exeqüibilidade, aplicabilidade, e efetividade da Lei de Reforma Psiquiátrica, por reafirmar precisamente qual o paradigma a ser transposto, o que, esperamos, propiciará que o avanço da linha antimanicomial não implique no retrocesso da qualidade, humanização, acesso e controle social, indicativo de sua organicidade para com a construção de um Sistema Único de Saúde, público, de amplo acesso, eficaz, cidadão e com controle social.

\section{O PARADIGMA DA EXCLUSÃO}

O Decreto-lei n. 24.559, de 3 de julho de 1934, já dispensava tratamento ao doente mental como caso de polícia e de ordem pública, conquanto permitia a internação por mera requisição da autoridade policial.

No mesmo sentido os Códigos Penal e de Processo Penal de 1940, ao estabelecerem medida de segurança ao doente mental considerado perigoso, inobstante absolvido da imputação que se the atribuía, quando praticasse os chamados quase-crimes ${ }^{(1)}$ (crime impossivel por absoluta ineficácia do meio empregado, por exemplo), coisa que para o considerado "normal" redundaria em absolvição pura e simples.

Tal modelo é o resultado do conceito de doente mental e de tratamento até então estabelecidos.

(1) NORONHA, E. Magalhães. “Direito penal”, 19ª ed., São Paulo: Saraiva, 1981, v. 1, p. 334. 
Francisco Paes Barreto(2), ao abordar o tema, traduz bem o problema: "Doente mental é aquele que infringiu pautas de comportamento ou as pautas existenciais socialmente definidas ... Nesta perspectiva o transgressor deve ser punido, como reparação e corrigenda".

O modelo assistencial psiquiátrico do final da década de 1940 caracteriza-se pelo desrespeito aos Direitos Humanos, tornando-se, ao longo dos últimos duzentos anos, ícone, emblema da exclusão e seqüestro da cidadania, os hospitais psiquiátricos.

Um modelo de atenção inadequada, como o que se observou nos últimos séculos com relação ao doente mental, não pode ser superado tãosomente com a eleição de um ícone e contra ele única e exclusivamente direcionar todas as nossas inconformidades. Não significa negar que o manicômio é o ícone materializador do paradigma a ser substituído; porém, necessário conhecer como e porquê ele se transformou em um ambiente de exclusão. É sobre o quê discorreremos nas duas seções seguintes.

\section{O MANICÔMIO E A EXCLUSÃO}

Nos primórdios da civilização, as sociedades primitivas consideravam os indivíduos com transtornos mentais como emissários da divindade, demonstrando tolerância para com a diferença. Desde a antiga Mesopotâmia, do Egito antigo, entre os hebreus e os persas, a "loucura" era concebida como condição de proximidade com o divino. A intolerância tem seu marco referencial na Idade Média. O descontentamento político e religioso da época levou à Reforma Protestante e à Renascença, e ao Concílio de Trento, com a manutenção dos dogmas católicos, e à elaboração do Index (lista de livros proibidos aos católicos), à restauração dos Tribunais do Santo Ofício e à fundação da Companhia de Jesus, os Jesuítas.

Liderado por Ignácio de Loyola, um grupo extremamente místico da Universidade de Paris concebeu aquela organização, e com o lema "Lutar por Deus e pela cruz", difundiu a fé católica (catequese) nas colônias européias.

Por meio do obscurantismo e da ameaça, a humanidade viveu uma era de trevas, da qual é representativa a obra Maleus Maleficarum (Martelo das Feiticeiras), escrita em 1485 e consagrada como a Bíblia da Santa Inquisição, aprovada pelo papa Inocêncio VIII, e em seguida pelo rei de Roma Maximiliano I, em 1486, e pela Faculdade de Teologia da Universidade de Colônia em 1487. Ela foi assumida, assim assim pela Igreja, Monarquia e Universidade.

Tal cenário constitui-se no substrato para os três grandes eixos de preconceito, exclusão e intolerância da "loucura" até os nossos dias: 1) a suposta incapacidade do louco; 2) a suposta irresponsabilidade do louco; e 3) a suposta violência do louco.

(2) BARRETO, Francisco Paes. "Reforma psiquiátrica \& movimento Lacaniano". Belo Horizonte: Ed. Italiana, 1999, p. 49. 
Com a Renascença, houve reação e enfrentamento com a magia, através da reabilitação dos valores gregos. No período seguinte, na "Era da Razão e da Observação", durante o século XVII, a polarização deu-se entre o raciocínio dedutivo, analítico e matemático, e o método empírico e indutivo.

René Descartes, em seu "Discurso sobre o método", de 1637, e seu enunciado cogito ergo sunt (penso logo existo), lançou as bases do moderno racionalismo, o qual, no período seguinte, levou ao lluminismo, pelo qual a crença na razão substituiria a tradição e a fé.

Nesse período, ocorreram as grandes classificações. A Química foi sistematizada por Antoine Lavoisier e Carolus Linnaeus, com o "Systema Naturae", colocando o homem na ordem Primatae e batizando-o de Homo Sapiens.

Nesta esteira, o médico Philippe Pinel, na França do final do século XVIII, logo após a Revolução, por incumbência da Assembléia Francesa, passou a ordenar os excluídos de toda a ordem que se misturavam em Bicêtre (1793) e Salpêtrière (1795).

Pinel, desacorrentando e alimentando os internos, passou a discriminar os casos sociais das anomalias, estabelecendo a seguinte classificação: 1) melancolias; 2) manias sem delírio; 3) manias com delírio; e 4) demências.

Esta classificação de Pinel é o marco inaugural da Psiquiatria, que transformou a diferença humana em patologia.

A partir daquelas referências, Pinel criou o Tratamento Moral, primeiro método terapêutico para a loucura na modernidade, baseado em confinamentos, sangrias e purgativos, consagrando assim o hospital psiquiátrico (hospício ou manicômio) como o destino social dos loucos.

No século XIX, Durkheim define a loucura como "anomia social", consubstanciando a busca de uma causa biológica para a loucura, para tornar convincente sua inserção no campo das Ciências Naturais, na Medicina.

No final do mesmo século XIX, a exclusão e os maus-tratos do hospital pineliano geraram pesadas críticas, começando assim a ser criados espaços fora dos limites das cidades, onde os "anomistas sociais", em que pese continuassem ocultos e excluídos, pudessem circular com mais "liberdade" e ser "tratados e recuperados" através do artesanato e do trabalho agropastoril.

Sigmund Freud, médico austríaco, trouxe nova proposição, sobre outra dimensão - inconsciente - na condição humana, iniciando a formulação da Psicanálise, estabelecendo a polaridade com as ciências biológicas que perdura até os dias de hoje.

Contudo, Freud não conseguiu romper com a referência mecanicista de seu tempo, conquanto seu sistema de compreensão foi construído sobre o que denominou "aparelho mental", composto por id, ego e super ego, com o quê permaneceu o hospital psiquiátrico como locus social dos loucos e dos seus padecimentos. 
Ao longo do século $X X$, com o Marxismo e a Psicanálise, foram implementados os seguintes modelos mais significativos: 1) a Comunidade Terapêutica (1946 e 1959); 2) a Análise Institucional (1940 e 1952); 3) a Psiquiatria de Setor (1960); 4) a Psiquiatria Comunitária (J. F. KennedyGerald Caplan EUA, 1963); 5) a Antipsiquiatria (1966); e 6) a Psiquiatria Democrática (Reforma Psiquiátrica, Franco Basaglia, Itália, 1969).

O psiquiatra italiano Franco Basaglia, nos hospícios das cidades de Gorizia e depois Trieste, no norte da Itália, logrou a superação do modelo asilar-carcerário por uma rede diversificada de Serviços de Atenção Diária em Saúde Mental de Base Territorial e Comunitária.

No Brasil, o início da assistência psiquiátrica pública data da segunda metade do século XIX, ainda durante o período do Império, antes do que a assistência era leiga e asilar, prestada por instituições da Igreja.

Em 5 de dezembro de 1852 foi inaugurado o Hospício Pedro II, pelo próprio Imperador D. Pedro II, quando da declaração de sua maioridade, seguida de coroação, na cidade do Rio de Janeiro, consolidando e reproduzindo no solo brasileiro o modelo do hospital psiquiátrico europeu com uma política de tutela e segregação do doente mental(3).

Naquele ano, de 1852, por influência da psiquiatria francesa, linha de Esquirol, se tem a primeira lei sobre doente mental.

Em 15 de novembro de 1889, com a proclamação da República pelo Marechal Deodoro da Fonseca, Igreja e Estado deixaram de ser atrelados, cabendo então a administração dos hospícios aos médicos. Com a abolição da escravatura, preconizada por Campos Sales no início da Primeira República, as cidades cresceram em tamanho e complexidade, ocasionando a necessidade do poder público de aumentar o aparelho de contenção social.

$\mathrm{Na}$ área de Saúde Pública, a Oswaldo Cruz coube sanear a Capital da República quanto a endemias, notadamente a febre amarela.

Ao alienista Juliano Moreira, no Rio de Janeiro, competiu "sanear" a cidade com o recolhimento dos loucos às fazendas (hospitais-colônia).

A partir de 1890 a tutela desenvolve-se com a criação do Serviço de Assistência Médica dos Alienados e da legislação obtida a partir do Código Civil de 1916 e da Lei de 1919. Por essa legislação é fácil perceber uma série de tentativas de controlar esse grupo de pessoas, considerado prejudicial ao convívio da população. O Estado, nesse período, nada faz para assegurar direitos sociais, mas intervém quanto ao doente mental ${ }^{(4)}$.

Em 1923, foi criada a Liga Brasileira de Higiene Mental, propondo ações de higiene mental (humanização), apoiada no racismo.

(3) MARSIGLIA, Regina G. "Os cidadãos e os loucos no Brasil: a cidadania como processo". In: Saúde mental e cidadania, $2^{a}$ ed. São Paulo: Mandacaru, 1987, p. 18.

(4) Id. ibid. 
Até a primeira metade do século $X X$, o crescimento da Psiquiatria ocorre no âmbito das instituições públicas e é orientada para as pessoas pobres.

Em 1930, o Presidente Getúlio Vargas cria o Ministério da Educação e Saúde, adotando como principal medida quanto aos "doentes mentais" a edição do Decreto n. 24.559, de 3 de julho de 1934, que em seus arts. 50, $10,21,26$ e 33, concebia a "doença mental" como caso de polícia e de ordem pública, conferindo aos psiquiatras poderes amplos sobre o "doente mental", e até mesmo o direito de questionar ordem judicial, dispondo ainda a perda da cidadania do louco, promovendo o aumento das instituições psiquiátricas privadas e dos loucos oriundos de famílias abastadas.

Por força do Decreto-lei n. 591, de 3 de agosto de 1938, foi criado o Instituto de Psiquiatria ligado à Universidade do Brasil, no Rio de Janeiro, a partir de então a formação dos médicos passa a acontecer na Academia, destinando os hospitais psiquiátricos aos experimentos, tais como Psicocirurgia, Eletroconvulsoterapia (eletrochoque), Malarioterapia e Insulinoterapia.

Em 1940, com o Código Penal e o Código de Processo Penal, estabelece-se o conceito de periculosidade e recomenda-se o recolhimento do doente mental ao manicômio, e dos indivíduos considerados perigosos às casas de custódia ou colônias agrícolas. Note-se que não há ênfase na recuperação e tratamento dos indivíduos, o Estado só os segrega.

Por meio do Decreto-lei n. 3.171, de 2 de abril de 1941, regulamentado pelo Decreto-lei n. 7.055/41, foi criado o Serviço Nacional de Doenças Mentais - SNDM, o qual fomentou, até o final da década de 50, a instalação e ampliação de hospitais-colônia em todo o Brasil.

A partir de 1950, com a criação do Instituto de Aposentadoria e Pensões dos Trabalhadores da Indústria - IAPI - e dos trabalhadores do comércio IAPC - dá-se novo incremento na internação em sanatórios privados ${ }^{(5)}$.

Por intermédio da Lei n. 1.920, de 25 de julho de 1953, o Presidente Vargas cria o Ministério da Saúde, e no final da década de 50, início dos anos 60, é importado dos Estados Unidos o conceito de Medicina Preventiva, mas somente como discurso formal, dissociado da prática asilar-carcerária.

Na década de 50, a Organização Mundial da Saúde - OMS, órgão da ONU criado após a II Guerra Mundial, recomendou o "investimento em ações de saúde mental" e a adoção do termo "saúde mental" ao invés de "doença mental", baseada em estudos que revelaram o custo excessivo da "doença mental", incorporando assim a assistência psiquiátrica à Saúde Pública e constituindo a Psiquiatria Comunitária.

No início da década de 50 foi sintetizado o primeiro medicamento neuroléptico para psicose, a Clorpromazina, comercializada com o nome de Amplictil, logo chamados tais medicamentos de "camisa-de-força química" ou popularmente de "sossega-leão". 
Afirma Barreto(6) que ao servir de abrigo para a rejeição, o hospital transforma-se em depósito de pessoas, consideradas como retalhos humanos. Sua função passa a encobrir partes frágeis da comunidade, evitando o contraste que poderia ser criador. A comunidade sente-se aliviada ao trancar nos hospitais psiquiátricos aquelas características condenadas por sua censura. Assim procedendo, vive-se a ilusão de que nada daquilo tem a ver consigo e a existência de pessoas segregadas embala essa tranqüilidade ${ }^{(7)}$.

Essa forma de ver e tratar o problema - aliás, comum em termos de atenção pública de saúde, como se internação hospitalar fosse a panacéia para todos os males - só se presta para revelar trágicas estatísticas acerca do tratamento dispensado ao doente mental e da falta de resolutibilidade desse tratamento.

O ano de 1960 foi consagrado como "Ano Internacional da Saúde Mental", sendo os anos 60 de importância especial na compreensão da assistência psiquiátrica brasileira no final do século $X X$, após o suicídio de Vargas, com o período de crise, houve a euforia da fase desenvolvimentista do período Juscelino Kubitscheck, os anos dourados, e apesar disso, a população internada nos manicômios brasileiros aumentava.

Em 1950, eram 24.234, em 1955, foi a 34.550 e, em 1960, chegou a 49.173 pessoas internadas.

O quantitativo de hospitais psiquiátricos no Brasil era nenhum em 1852, chegando a 54 públicos e 81 privados em 1961, totalizando 135, contra acanhados 17 ambulatórios de psiquiatria em todo o território nacional, conforme dados do Ministério da Saúde.

Em 1971, somavam 72 públicos e 269 privados com 80.000 leitos. Em 1981, eram 73 públicos e 357 privados, chegando a 100.000 leitos.

Francisco D. M. de Moura Neto, com base em dados do IBGE de 1983, informa que o Brasil possuía 427 hospitais psiquiátricos, totalizando 106.605 leitos, dos quais 40.708 localizados no Estado de São Paulo, com 163 hospitais. Segundo levantamento feito em $1981,80 \%$ da população internada tinha, já naquela época, mais de seis meses de internação. É sabido, prossegue ele, que esses hospitais funcionam em precárias condições, sem fiscalização sequer dos órgãos sanitários responsáveis pelo seu gerenciamento, constituindo-se em espaço de violência e de destruição institucionalizados, legitimados e reconhecidos pelo Estado como "espaços terapêuticos", e o que é pior: gerando riqueza para os donos desses hospitais ${ }^{(8)}$.

Somente a partir da redemocratização do país e início da Reforma Sanitária e Reforma Psiquiátrica começou a diminuir o ritmo da escalada

(6) BARRETO, Francisco Paes, op. cit., p. 48.

(7) Id. ibid., p. 43.

(8) MOURA NETO, Francisco Drumond Marcondes de. "Bases para uma reforma psiquiátrica".

In: Saúde mental e cidadania, 2ª ed., São Paulo: Mandacaru, 1987, p. 63. 
de hospitais e leitos psiquiátricos contratados, refluindo em 1991 para 54 públicos e 259 privados e 88.000 leitos, e em 1999 a 50 públicos e 210 privados e 68.000 leitos, e em julho de 2001 a 66.000 leitos.

Ocorreu que, a partir do golpe militar de 1964, adotou-se política de privatização maciça, criando o INPS em 1966, durante o governo Castelo Branco, implementado efetivamente no governo Costa e Silva e seguida tal política de assistência à saúde pelos que o sucederam.

Durante os anos 60-70, fomentou-se o surgimento das "Clínicas de Repouso", eufemismo dado aos hospitais psiquiátricos, e adotaram-se métodos de busca e internamento de pessoas que chegaram, por exemplo, ao ponto de ambulâncias percorrerem as cidades, especialmente após clássicos de futebol, identificando indivíduos que portassem a carteira do INPS e que estivessem dormindo embriagados na via pública, os quais eram levados e internados com o diagnóstico de "psicose alcoólica"!

Note-se que eram pessoas produtivas e socialmente inseridas, porquanto portadoras de carteira profissional, internadas sob o discurso preventista da recém-criada e rendosa indústria da loucura, que acrescentou às representações de irresponsabilidade, incapacidade e periculosidade, a de lucratividade do louco.

Fácil perceber que o hospital psiquiátrico, tal como concebido, pouco ou nada contribuiu para a recuperação do paciente, ou sua reinserção social. A instituição assumiu características pura e simplesmente asilares. Não admira que se visse, e ainda se veja, nas comunicações de internação do hospital psiquiátrico público de Porto Alegre a expressão "paciente morador do hospital", ou seja, de regra, no manicômio se entra e lá se permanece.

Esse descaso com o portador de sofrimento psíquico é diretamente proporcional à debilidade do conceito de cidadania vigente em nosso corpo social geral, que os mecanismos de controle, opressão e exclusão do doente mental não necessitam de muitas justificativas tecnojurídicas ${ }^{(9)}$.

Nessa linha de raciocínio, sustenta Barreto(10) ter sido, e ainda ser, o diagnóstico psiquiátrico baseado em critérios políticos, culturais e morais, exemplificando com o fato de o homossexualismo, por si só, ter deixado de ser considerado doença mental apenas em 1974 pela Associação Americana de Psiquiatria, e o tabagismo só foi considerado toxicomania pela CID 10 (a última, e ainda em vigor, editada em 1993). A inclusão ou exclusão revela critérios que nada têm de científicos.

Percebe-se, dessa forma, que tanto o diagnóstico, quanto a internação no hospital psiquiátrico se presta, não raro, a objetivos outros que não a recuperação ou melhoria das condições de vida do paciente. $O$

(9) KINOSHITA, Roberto Tirakoski. "Uma experiência pioneira: a reforma psiquiátrica italiana". In: Saúde mental e cidadania, $2^{a}$ ed., São Paulo: Mandacaru, 1987, p. 82.

(10) BARRETO, Francisco Paes, op. cit., pp. 196-197 e 213. 
desrespeito ao ser humano é levado a tal extremo que já se pode observar, em visita à clínica psiquiátrica, a presença de uma adolescente em ala fechada com grades, porque, segundo ela, a mãe queria the demonstrar que, em casa, recebia um tratamento do qual não deveria reclamar. Obviamente o caso foi encaminhado à Promotoria de Defesa da Infância e da Juventude e a alta providenciada imediatamente, mas o exemplo bem demonstra no que se transformou o hospital psiquiátrico. Ora, um mero desajuste de conduta é capaz de desencadear o diagnóstico e a internação. Tudo isso não só pela instituição manicomial em si, mas por obra de sua real clientela que será abordada na seção seguinte.

\subsection{MANICÔMIO E MERCANTILIZAÇÃO DO SOFRIMENTO}

Como já referido na anterior seção, apesar da redução de cerca de 37.000 leitos de internação psiquiátrica e criação de aproximadamente 266 Serviços Substitutivos, o modelo tradicional ainda prevalece. Este grupo de morbidade constitui o $4^{\circ}$ maior nos gastos do SUS, tendo consumido, no ano de 2001, aproximadamente $R \$ 470$ milhões, sendo que apenas $10 \%$ deste valor são dispendidos com os serviços substitutivos, sendo os restantes $90 \%$ ainda destinados ao financiamento das internações.

Há que se focar criticamente, além da própria internação, a duração do confinamento, conforme ressaltado por Barreto ${ }^{(11)}$, segundo o qual um psicótico pode constituir problema mais social do que psiquiátrico; explicitado pelo autor com a situação de um paciente que passa longo período longe da família, esta se reestrutura e acostuma a viver sem o elemento excluído, tornando difícil a reinserção.

Na visão do mesmo autor ${ }^{(12)}$, este é um dos fatores que explica por que, atualmente, o número de internações nada tem a ver com o critério psiquiátrico de atendimento. As internações se determinam, por exemplo, por pressão de órgãos policiais e de assistência social, que chegam a abandonar o paciente na porta do hospital; pressão dos familiares que vêem na internação a possibilidade de livrar-se temporária, ou definitivamente, de paciente indesejável.

A mercantilização do tratamento da saúde, e a ampliação dos benefícios ofertados pelos planos de saúde sociais e públicos, sendo que estes passaram a comprar serviços da rede privada para atenção aos seus associados, fez com que, nas décadas de 60 e 70 do século passado, o doente mental, que nas décadas anteriores foi tutelado e considerado improdutivo, se tornasse importante instrumento de lucro para o setor privado de prestação de serviços de saúde ${ }^{(13)}$.

(11) Id., ibid., p. 190.

(12) Id., ibid., p. 191.

(13) MARSIGLIA, Regina G, op. cit., p. 26. 
O doente se transformou em mercadoria e a sua doença se transformou em fonte de lucro, perpetuando com essa condição a manutenção de um sistema assistencial que, na realidade, foi criado para esta finalidade lucrativa, e não para recuperar sua saúde ${ }^{(14)}$.

De outra banda, Erving Goffmann, cientista social do departamento de sociologia da Universidade da Califórnia em Berkcley, após trabalho de pesquisa em estabelecimentos psiquiátricos de Washington nos anos de 1954 a 1957, onde descreve o mundo social do internado, anota que na sociedade não há hospitais psiquiátricos só porque supervisores, psiquiatras e auxiliares desejem empregos; há hospitais psiquiátricos porque existe um mercado para eles. Se em determinada região forem eliminados todos os hospitais psiquiátricos, os parentes, a polícia e os juízes pedirão a criação de outros hospitais; os verdadeiros clientes do hospital psiquiátrico exigirão uma instituição para atendimento de suas necessidades ${ }^{(15)}$.

Sem prejuizo do alertado por Erving Goffmann, conforme acima referido, o fato de a comunidade recorrer ao hospital psiquiátrico com o propósito de ajudar o paciente ocorre numa freqüência muito menor do que se supõe. É comum o psiquiatra colher as informações trazidas pelos parentes, ou acompanhantes do paciente, e tomá-las como efetivas, numa atitude crédula que leva à visão distorcida do paciente. Embora na maioria das vezes surja da família a iniciativa da internação, raramente seus propósitos são questionados. Felizmente, nos últimos anos, isso tem mudado, fazendo com que os profissionais de saúde mental, por meio de entrevistas e de observação das atitudes dos familiares, identifiquem as reais intenções, e quando o desejo de ajudar o paciente é o principal, as atitudes tanto do psiquiatra, quanto da família e do próprio paciente, tendem a fazer do atendimento extramural (ambulatório, consultório) a alternativa preferida(16).

O problema então, é o posicionamento da sociedade, da família e do Estado em relação ao doente mental. Nossa tendência de excluir, segregar e punir o diferente, pelo simples fato de ser diferente do estabelecido nas pautas sociais, e não pelos efetivos danos que possa causar ao corpo social. Nossa falta de solidariedade em aceitar e incluir aqueles que, posto apresentem necessidades especiais, têm outras potencialidades que bem direcionadas podem Ihe assegurar existência digna. Percebe-se, pois, que o verdadeiro paradigma a ser transposto não é o manicômio, mas a exclusão, porque acabar, pura e simplesmente, com os hospitais psiquiátricos não resgata a cidadania e a dignidade do portador de sofrimento psíquico. Talvez o fato de não se ter identificado precisamente o paradigma a ser superado, e de se buscarem novas alternativas ainda com a visão do velho paradigma, explique as dificuldades de superação da exclusão que serão tratadas na segunda parte deste ensaio.

(14) MOURA NETO, Francisco Drumond Marcondes de, op. cit., p. 59.

(15) GOFFMANN, Erving. "Manicômios prisões e conventos", $5^{\mathrm{a}}$ ed., Traduzido por Dante Moreira Leite. São Paulo: Perspectiva, 1996, p. 311.

(16) BARRETO, Francisco Paes, op. cit., p. 47 


\section{TRANSPOSIÇÃO DA EXCLUSÃO}

Transpor a exclusão passa, necessariamente, por uma adaptação geral às formas de se encarar o homem e o mundo nesse início de século. A vida em sociedade requer, cada vez mais, o estabelecimento de regras claras de convivência e a integração de todos os indivíduos na formulação e emprego dessas regras, fortalecendo-se, assim, a cidadania em geral.

O avanço da cidadania dos doentes não ocorrerá se não houver um avanço como um todo da cidadania de todos os segmentos da população ${ }^{(17)}$. A noção de cidadania no Brasil sempre esteve muito ligada à forma como o indivíduo se insere no mercado de trabalho. Isto fez com que se criassem barreiras muito maiores para o desenvolvimento da cidadania do doente mental(18). Lembre-se, a propósito, que direitos para os trabalhadores só surgiram a partir de 1934. E os doentes mentais que nem trabalhadores eram, não tinham direito ao trabalho, nem à profissão, e menos ainda à cidadania. Destarte, as possibilidades de resgate da cidadania e de inserção de quem sofre de transtornos mentais, envolvem a revisão das representações de irresponsabilidade, incapacidade e periculosidade que sempre os rotularam.

\subsection{INSERÇÃO DAS PESSOAS QUE SOFREM}

Separar os mitos e preconceitos e evitar os rótulos, que sempre envolveram a doença mental, da realidade, embora não solucionem de todo o problema, constitui um grande passo em direção ao resgate proposto.

Quanto à periculosidade, esta não é própria do transtorno mental, mas de alguns casos somente. Alguns portadores de sofrimento psíquico podem cometer crimes graves, mas também é verdade que os tidos como normais cometem um número bem maior dessas infrações ${ }^{(19)}$. O paciente psiquiátrico pode constituir perigo real para a família e para a comunidade. Esta noção é bastante conhecida. O que ainda não foi suficientemente esclarecido e divulgado é o tanto que esse perigo é imaginário, e o tanto que o louco é agredido pela sociedade que nele vê refletida sua própria agressividade ${ }^{(20)}$.

A superação da periculosidade presumida aos envolvidos em infrações penais pela Lei n. 7.209/84, que reformou a parte geral do Código Penal, exigindo para aplicação de medida de segurança a comprovação pericial da efetiva periculosidade, além de prova cabal da ilicitude da conduta, é um expressivo avanço legislativo nesse sentido. Não obstante, ainda há um senti-

(17) MARSIGLIA, Regina G., op. cit., p. 13-14.

(18) Id., ibid., p. 27-28.

(19) BARRETO, Francisco Paes, op. cit., p. 194.

(20) Id., ibid., p. 48. 
mento social geral de presunção de periculosidade do doente mental que precisa ser superado, pois do total de portadores de sofrimento psíquico apenas uma pequena parcela é, realmente, perigosa, além do que, se adequadamente tratados, podem perfeitamente ser inseridos.

O Projeto de Atenção Interdisciplinar ao Paciente Judiciário - PAIPJ - do Tribunal de Justiça de Minas Gerais, cuja experiência é relatada por Fernanda Otoni de Barros, no Caderno de Textos da III Conferência Nacional de Saúde, realizada em Brasília em dezembro de 2001, é exemplo do referido no parágrafo anterior.

Da III Conferência Nacional de Saúde Mental, realizada em Brasília-DF no período de 11 a 15 de dezembro de 2001, tivemos a honra de participar como Delegado e Relator de Grupo de Trabalho, após indicação dos Promotores de Justiça da região quando de nossa participação no Seminário Direito à Saúde Mental - Regulamentação e Aplicação da Lei n. 10.216, em Brasília, no período de 22 e 23 de novembro de 2001 , oportunidade em que a experiência do Tribunal de Justiça mineiro foi exposta por Fernanda(21), informando que, dos 160 casos de medida de segurança atendidos, o índice de reincidência é zero. Desses, 111 estão sentenciados com medida de segurança ou aguardando a sentença. Os outros quarenta e nove cumpriam pena em penitenciária e manifestaram o sofrimento psíquico no decorrer da pena. Setenta e quatro por cento dos atendidos já estão cumprindo a medida de segurança em casa, junto a seus familiares, trabalhando, circulando livremente pela cidade, cumprindo uma medida de segurança de tratamento ambulatorial. Dos 27 casos que ainda estão em regime de internação, setenta por cento estão exercendo atividades do Programa de Inserção Social do PAI-PJ, ou seja, passando os fins de semana e datas comemorativas com seus familiares e saindo durante a semana para participar de atividades na cidade junto com o acompanhamento terapêutico da equipe. Em todos os casos houve a manifestação de um sofrimento anunciado, porém, por não se terem identificado os anúncios, o crime foi a única forma de obterem alguma intervenção. Eram casos que antes da intervenção do programa estavam fechados no manicômio judiciário, com diagnóstico de altíssima periculosidade.

Demonstrado pelo programa de atenção ao paciente judiciário de Minas Gerais que é possivel a reinserção e o resgate da cidadania do portador de sofrimento que praticou crime (e em alguns casos crimes gravíssimos), por que não seria de todos os demais portadores de sofrimento psíquico que sequer têm diagnóstico de periculosidade? Não há dúvida de que é possível, mas Estado e sociedade têm que vencer as barreiras do preconceito. Hodiernamente, cidadania não é mais um atributo dos iguais, dos normais, dos que podem decidir de forma convencio-

(21) BARROS, Fernanda Otoni de. PAI-PJ - Projeto de Atenção Interdisciplinar ao Paciente Judiciário. In: Conferência Nacional de Saúde Mental, 3, 2001, Brasília. Caderno de Textos. Brasília: Ministério da Saúde, 2001, pp. 118-119. 
nal, os diferentes também devem ter seus direitos garantidos ${ }^{(22)}$. 0 simples fato do diagnóstico de doença mental ou da internação em clínica psiquiátrica não deve implicar a perda da capacidade civil ${ }^{(23)}$.

Um verdadeiro trabalho de recuperação do doente mental crônico deve ser referenciado no resgate de sua identidade pessoal, social e cultural(24). No paciente não está a única, nem sequer a principal razão de sua internação, embora haja tendência de atribuir o fato à sua doença mental. Abstraí-lo de seu mundo e estudá-lo como indivíduo isolado é cometer aprioristicamente uma cisão. É necessário incluir, pelo menos os familiares e os integrantes do corpo assistencial. $O$ que se tem feito, porém, visa discriminá-lo e reduzi-lo a mero objeto de tratamento. Quase todas as possibilidades de se efetivar sua condição de sujeito estão bloqueadas ${ }^{(25)}$. A implantação do modelo substitutivo de saúde mental proposto pela reforma psiquiátrica constitui-se em importante passo no sentido de resgatar a cidadania do portador de sofrimento psíquico, coisa esquecida no modelo de segregação hospitalar.

Os Serviços Territoriais de Atenção Diária em Saúde Mental, de base comunitária (Centros e Núcleos de Atenção Psicossocial - CAPS/NAPS), as Oficinas Terapêuticas, as Oficinas de Capacitação/Produção, os Ambulatórios de Saúde Mental, as Equipes de Saúde Mental em Hospitais Gerais, as Moradias Terapêuticas, os Centros de Convivência, o atendimento ambulatorial, o hospital-dia e os serviços de urgência permitem o acompanhamento da evolução do paciente e a intervenção da equipe de saúde mental sem retirá-lo do convívio familiar e de suas ocupações habituais. $O$ convívio e a interação com a família e a comunidade evitam a perda dos vínculos, estes essenciais para a recuperação, que certamente ocorre na internação tradicional. O tratamento em unidades psiquiátricas de hospitais gerais, propicia uma atenção integral à saúde do paciente, pois portador de sofrimento psíquico também pode ser acometido de problemas cardíacos, neurológicos, pulmonares, infecções que o hospital psiquiátrico não tem equipamentos nem pessoal especializado para o diagnóstico e terapia dessas doenças, além do que, é muito mais fácil dotar o hospital geral de assistência psiquiátrica adequada do que aparelhar o hospital psiquiátrico para atendimento médico complexo ${ }^{(26)}$. Os centros de convivência, as moradias protegidas, as cooperativas de trabalho que impliquem constituição de empresas sociais que garantam trabalho e remuneração, como elementos integradores e organizadores dos sujeitos na vida societária, são auxiliares

(22) PITTA, Ana Maria Fernandes; DALLARI, Sueli Gandolfi. "A cidadania dos doentes mentais no Sistema de Saúde do Brasil”. Saúde em Debate, Londrina, n. 36, p. 21, out. 1992.

(23) Id., ibid., p. 22.

(24) MOURA NETO, Francisco, op. cit., p. 64.

(25) BARRETO, Francisco Paes, op. cit., p. 58.

(26) Id., ibid., p. 188. 
primorosos para que se busque a eqüidade nas estruturas assistenciais disponíveis ${ }^{(27)}$, valorizando o paciente e quebrando o estigma de representar apenas um peso morto para a familia e para a comunidade.

A perfeita compreensão e aplicação do Sistema Único de Saúde, nos moldes propostos pela Constituição Federal, especialmente em seus arts. 196 a 200, pela Lei n. 8.080/90, pelas Normas Operacionais Básicas - NOB e Normas Operacionais de Assistência em Saúde - NOAS, com efetiva descentralização e municipalização do atendimento, têm contribuído, e muito mais pode render para a otimização do atendimento em saúde como um todo, inclusive da saúde mental. Mas é necessário que se tenham presentes conceitos como gestão, constante da NOB/SUS 01/96, e planejamento de ações com base em critérios epidemiológicos. Não se está aqui a dizer que nada foi feito desde a edição dessas normas; ao contrário, muito se fez. Não obstante, ainda há um longo caminho a ser percorrido, e muito mais se poderia ter obtido a partir de estratégias simples de atenção preventiva, passíveis de serem implementadas em qualquer município, desde que se veja o problema com olhos de quem tem interesse e responsabilidade de resolvêlo. Anote-se, por exemplo, que a maioria dos medicamentos utilizados para tratamento de transtornos mentais estão na lista de medicamentos da farmácia básica, que é de responsabilidade dos municípios. Nesse sentido, o fortalecimento do controle social, regulamentado pela Lei n. 8.142/90, por meio dos conselhos comunitários, da família e dos próprios usuários dos serviços de atenção à saúde mental, é indispensável para que as normas saiam do papel. Não é diferente com as leis específicas de saúde mental que buscam reverter esse quadro, como veremos no item a seguir.

\subsection{EXEQÜIBILIDADE, APLICABILIDADE E EFETIVIDADE DA LEI DE REFORMA PSIQUIÁTRICA}

No Rio Grande do Sul, a Lei Estadual n. 9.716, de 30 de junho de 1992, é fruto de projeto de lei de autoria do então Deputado Estadual Marcos Rolin - PT, projeto este formulado e discutido com o Fórum Gaúcho de Saúde Mental, instância estadual do Movimento Nacional da Luta Antimanicomial. O Estado do Rio Grande do Sul foi pioneiro no estabelecimento de uma legislação psiquiátrica que contemplasse a nova forma de ver e dar atenção à saúde mental(28).

No mesmo sentido, a partir de 1992, passaram a viger outras sete leis estaduais, do Ceará, Distrito Federal, Espírito Santo, Minas Gerais, Paraná,

(27) PITTA, Ana Maria Fernandes; DALLARI, Sueli Gandolfi, op. cit., p. 20.

(28) DIAS, Miriam Thais Guterres. "Os (des)caminhos da política de saúde mental no Rio Grande do Sul: uma análise da implantação da Lei de Reforma Psiquiátrica", 1997, 147 f. Dissertação (Mestrado em Serviço Social) - Faculdade de Serviço Social, Pontifícia Universidade Católica, Porto Alegre, 1997, f. 75. 
Pernambuco, Rio Grande do Norte, além da referida lei do Rio Grande do Sul, todas inspiradas no Projeto de Lei n. 3.657/89, de autoria do Deputado Paulo Delgado PT/MG, o qual somente foi aprovado em 27 de março de 2001, com substitutivo do Senado, prevendo a substituição gradativa do hospital psiquiátrico por serviços de atenção ambulatorial diária, leitos em hospitais gerais, notificação da internação involuntária e definição dos direitos das pessoas portadoras de sofrimento mental.

O Estado do Rio Grande do Sul, não obstante passados dez anos da aprovação da lei, ainda conta com 1.771 leitos em hospitais psiquiátricos, sendo 1.341 nos seis hospitais privados e 430 nos dois hospitais públicos. Como se vê, a concentração do atendimento hospitalar em instituições privadas dificulta a substituição gradativa do modelo hospitalocêntrico, segregador e de exclusão, por uma rede de serviços públicos abertos, porque isso implica o abandono de uma estrutura comercial pronta e rentável.

A falta de articulação de diversos gestores de saúde municipais que, seja por divergência partidária com outros níveis de governo, ou por entenderem que "louco se interna no São Pedro", ou ainda, pela velha falta de correspondência entre os serviços transferidos pela União e Estado e os recursos respectivos, não adotam as providencias necessárias para a implantação da rede de serviços substitutivos, mantendo-se, assim, a necessidade de permanência das instituições asilares existentes, consiste noutro aspecto que dificulta a completa implementação da lei. Apesar dos esforços desenvolvidos pela Secretaria Estadual da Saúde e da Associação de Secretários e Dirigentes de Saúde do Estado, ainda é pequeno o número de municípios que dispõem de atendimento especializado em saúde mental ou de leitos psiquiátricos em hospital geral.

Mais um obstáculo para os portadores de sofrimento psíquico é o problema que aflige a população carente em geral e não somente os ditos loucos, ou seja, o problema do acesso à Justiça, já que há consciência reinante de que a igualdade perante a lei é apenas formal, e que somente desfrutam dessa igualdade aqueles que têm força própria para fazer valer seus direitos.

Também contribui para o retardo em sua implementação o desconhecimento sobre a lei e as propostas nela inseridas. Mesmo a área de saúde pública, e na área jurídica, ainda há operadores que a desconhecem. O que dizer da comunidade e dos usuários.

O próprio Ministério Público, incumbido pelos arts. 10 e 11 da Lei $n$. 9.716 de fiscalizar as internações compulsórias e fazer vistorias nas unidades psiquiátricas, encontra entraves para a adequação de serviços, notadamente no interior do Estado, diante da ausência total dos serviços substitutivos, da ausência de leitos psiquiátricos disponíveis nos casos de necessidade de interdição de alguma unidade psiquiátrica vistoriada, e por vezes do despreparo do gestor local no próprio planejamento e gestão da saúde pública mental. 
Com o advento da Lei n. 10.216/2001 não foi diferente. O tempo de tramitação do projeto já fala por si. A iniciativa se deu e 1989 por parte do Deputado Paulo Delgado, e o substitutivo do Senador Sebastião Rocha só foi devolvido à Câmara em 1999, completamente modificado em face das diversas pressões que sofreu. Por exemplo, o projeto original previa a extinção progressiva dos hospitais psiquiátricos, impedindo a criação de novos leitos em instituições de caráter asilar.

Outro exemplo foi a supressão do projeto original da possibilidade de o Ministério Público, atendendo denúncia ou solicitação de familiar ou representante do paciente, designar equipe revisora multidisciplinar de saúde mental. Restaria, assim, vazia a disposição do $\S 1^{\circ}$ do art. $8^{\circ}$, que determina a comunicação ao Ministério Público das internações compulsórias. Ora, se a lei não explicita, ou, de outro modo, sabendo-se que o legislador, intencionalmente suprimiu a ação fiscalizadora correspondente à comunicação, poder-se-ia indagar por que a manteve!

Tal antinomia, evidente conflito aparente de normas, já que incumbido o Ministério Público, pela Constituição, de cobrar dos poderes públicos e dos serviços de relevância pública o efetivo respeito aos direitos do cidadão (CF, art. 129, II), e sendo as ações e serviços de saúde, públicas ou privadas, serviços de relevância publica (CF, art. 197), está o Ministério Público autorizado a promover todas as medidas necessárias à garantia dos direitos previstos, também na Lei n. 10.216/2001. No Rio Grande do Sul, por sua lei estadual, há previsão da instauração pelo Ministério Público de junta revisora para os casos de internação involuntária. E ainda que assim não fosse, poderíamos invocar o "Princípio 17" da Resolução da ONU, que estabelece órgão de revisão judicial ou outro independente e imparcial.

O texto, porém, como posto pode dar azo a equívocas contestações, notadamente quando comparado com a lei estadual do Rio Grande do Sul, por exemplo, que atribui ao médico que determinou a internação a responsabilidade de fazer a comunicação ao Ministério Público, enquanto a lei federal atribui o encargo ao responsável técnico pela instituição. Tal divergência, posto possa parecer meramente semântica, já foi causa de isenção de responsabilidade pela falta de comunicação da internação, como se viu na Apelação-Crime n. 70003516697, do Tribunal de Justiça do Rio Grande do Sul.

Outro conflito aparente de normas a ser enfrentado se dá entre a Lei de Reforma Psiquiátrica e a Lei de Execuções Penais, no que concerne à manutenção dos manicômios judiciais e o caráter duplo retributivo-ressocializante ou unicamente curativo-ressocializante das medidas de segurança, e ainda a natureza de proteção social ou proteção do indivíduo destas medidas.

\section{CONSIDERAÇÕES FINAIS}

A disposição de enfrentar, ainda que de modo a suscitar o debate crítico do tema, mais do que apresentar posicionamento pronto e acaba- 
do, foi de abordar a própria exeqüibilidade, aplicabilidade e especialmente efetividade da Lei de Reforma Psiquiátrica, a fim de que o avanço da linha antimanicomial não implique no retrocesso da qualidade, humanização, acesso e controle social, indicativo de sua organicidade para com a construção de um Sistema Único de Saúde, público, de amplo acesso, eficaz, cidadão e com controle social.

Entendemos, por conseguinte, que o resgate da cidadania das pessoas portadoras de sofrimento mental não se exaure com a extinção, pura e simples das instituições asilares. É certo que o manicômio pouco ou em nada contribuiu para a recuperação das pessoas acometidas de sofrimento mental, sendo, ao contrário, lugar de violação de seus direitos. Mas, o importante destacar, é a necessidade de uma mudança de visão do portador de sofrimento psíquico, não mais como um indivíduo perigoso, inválido e improdutivo. Superar o paradigma da exclusão para, com sentimento solidário e de quem busca uma sociedade justa e fraterna, oportunizar ao doente um tratamento digno, que valorize suas potencialidades e diminua seu sofrimento.

Significativo avanço na consolidação dos direitos das pessoas portadoras de sofrimento mental se deu com a legislação recentemente obtida, declarando sua cidadania mediante o reconhecimento dos seus direitos e explicitando as obrigações do Estado. Porém, é necessário que sociedade, família e Estado, conjuguem esforços para efetivar essas garantias, por meio do fortalecimento do controle social das ações e serviços de saúde, da municipalização do atendimento tornando-o cada vez mais próximo do usuário, da criação da rede substitutiva ao hospital psiquiátri$\mathrm{co}$, da articulação e qualificação constante de profissionais de saúde e profissionais do Direito que busquem facilitar a vida do usuário dos serviços e de seus familiares. É verdade que a lei, por si, não altera a realidade, mas permite o debate, o lançamento de idéias e propostas de solução para o problema.

Incumbe ao Ministério Público relevante papel, fiscalizando nas internações compulsórias, isto é, medidas de segurança, a legalidade e dignidade das instalações, impedindo que se converta em "prisão perpétua", e com o concurso de familiares, responsáveis e curadores, promover todas as modalidades de garantia aos direitos dos internados em geral, participando da formulação de políticas públicas e de instituições voltadas para a reabilitação psicossocial, fomentando a criação de serviços substitutivos ao manicômio.

Outrossim, cabe ao Ministério Público zelar pela qualidade dos serviços de relevância pública, onde se incluem as ações de saúde, e de outros interesses difusos e coletivos, o que abrange os interesses daqueles que se encontram em desvantagem social.

O presente momento é decisivo na implementação da Reforma Psiquiátrica no Rio Grande do Sul, eis que a sociedade gaúcha brada contra 
a falta de leitos psiquiátricos, instando através de associações, sindicatos médicos e da imprensa o Ministério Público a providências judiciais a fim de "garantir leitos para internações, ainda que particulares, a serem suportados pelo poder público", na contramão da Reforma Psiquiátrica, mas impelidos pela premência e desespero de situações que não podem esperar futuras correções nas políticas de saúde, podendo levar a um retrocesso indesejável no penoso caminho das conquistas de dignidade e cidadania das pessoas portadoras de sofrimento psíquico, isto porque não foram antes ou simultaneamente implantados os serviços substitutivos com quantidade e qualidade suficientes para acompanhar a redução de leitos psiquiátricos em manicômios, e muito menos foram abertos leitos psiquiátricos em hospitais gerais para os casos agudos que sempre existirão, ainda que em número infinitamente menor, mesmo quando já estiverem perfeitamente funcionando os serviços substitutivos. Outro fator que agrava sobremaneira todo o contexto do problema é a escalada das drogas, não só na quantidade como no potencial de dependência, como é o caso do "craque", e pelo alto índice de recaídas deste segmento, criando demanda interminável de leitos e de improvável solução restrita à esfera dos serviços substitutivos de saúde pública.

Para o fortalecimento da cidadania é fundamental o aperfeiçoamento cognitivo da matéria pelos membros do Ministério Público, propiciando atuação destes agentes sociais que já têm bagagem na tutela de tantos outros interesses difusos e coletivos da sociedade, podendo contribuir muito, na proporção do conhecimento do Direito Sanitário, na implementação das garantias dos que têm sofrimento psíquico, com o concurso imprescindível dos familiares e da própria sociedade na discussão e a elaboração de propostas e na luta pelo reconhecimento pleno da cidadania das pessoas portadoras de sofrimento psíquico.

\section{REFERÊNCIAS BIBLIOGRÁFICAS}

AMARANTE, Paulo D. Carvalho. "Loucos pela vida: a trajetória da reforma piquiátrica no Brasil", 2ª ed., Rio de Janeiro: Fiocruz.

BARRETO, Abalberto de Paula. "Depressão e cultura no Brasil". Jornal Brasileiro de Psiquiatria, n. 42, n. 1, 1993.

BARRETO, Francisco Paes. "Reforma psiquiátrica \& movimento Lacaniano". Belo Horizonte: Editora Italiana, 1999, 241 p.

BARROS, Fernanda Otoni de. PAI-PJ - Projeto de Atenção Interdisciplinar ao Paciente Judiciário. In: Conferência Nacional de Saúde Mental, 3, 2001, Brasília. Caderno de Textos. Brasília: Ministério da Saúde, 2001, pp. 113-120. 
CARAVANA Nacional de Direitos Humanos, primeira: uma amostra da realidade manicomial brasileira: relatório. Brasília: Centro de Documentação e Informação Câmara dos Deputados, 2000.

COSTA, Augusto Cesar de Farias; COSTA, Marisa Pacini; FONTENELLE, Jaqueline. "A experiência do Instituto de Saúde Mental". In: PITTA, Ana (Org.). Reabilitação psicossocial no Brasil. São Paulo: Hucitec, 1996.

DANIELE, Leo. "Direito alternativo, projeto incendiário". Catolicismo, n. 514, out. 1993.

DIAS, Miriam Thais Guterres. "Os (des)caminhos da política de saúde mental no Rio Grande do Sul: uma análise da implantação da Lei de Reforma Psiquiátrica". 1997, 147 f. Dissertação (Mestrado em Serviço Social) - Faculdade de Serviço Social, Pontifícia Universidade Católica, Porto Alegre, 1997.

FARIAS, Maria Eliane Menezes. "O papel do Ministério Público na defesa dos direitos do paciente e da qualidade da assistência em saúde mental". Palestra proferida na Abertura do Seminário Nacional sobre o Direito à Saúde Mental, Organização Pan-Americana de Saúde/OPAS, Brasília, 2001.

FIGUEIREDO, Ana Cristina; CAVALCANTI, M. Tavares. "A reforma psiquiátrica e os desafios da desinstitucionalização". In: Conferência Nacional de Saúde Mental de Brasília, 3. Rio de Janeiro: Edições IPUB, 2001.

FOUCAULT, Michel. "História da loucura na idade clássica". São Paulo: Perspectiva, 1978.

"Microfísica do poder". Rio de Janeiro: Graal, 1990.

"O nascimento da clínica". Rio de Janeiro: Forense, 1977.

GOFFMANN, Erving. "Manicômios prisões e conventos", $5^{\text {a }}$ ed. Traduzido por Dante Moreira Leite. São Paulo: Perspectiva, 1996, 312 p.

GUARESCHI, Pedrinho A. "Ética, justiça e direitos humanos". In: Psicologia, Ética e Direitos Humanos. Brasília: Comissão Nacional de Direitos Humanos, Conselho Federal de Psicologia, 1998, pp. 9-19.

KINOSHITA, Roberto Tirakoski. "Uma experiência pioneira: a reforma psiquiátrica italiana". In: Saúde mental e cidadania, $2^{\text {a }}$ ed., São Paulo: Mandacaru, 1987, pp. 67-83.

LEAL, E. M. "A noção de cidadania como eixo da prática clínica: uma análise do programa de saúde mental de Santos". 1994. Dissertação (Mestrado) Universidade do Estado do Rio de Janeiro, Rio de Janeiro, 1994.

"O debate sobre a 'natureza' da clínica na reforma psiquiátrica brasileira - algumas considerações iniciais sobre a relação desta questão com descrições essencialistas e idealizadas do sujeito". In: Venancio, A. T.; Leal, E. M.; Delgado, P. G. (Orgs.). O campo da atenção psicossocial. Rio de Janeiro: Te Corá Ed., Instituto Franco Basaglia, 1997, pp. 191-203.

LYRA, Roberto; ARAÚJO JÚNIOR, João Marcelo da. "Criminologia de acordo com a Constituição de 1988". Rio de Janeiro: Forense, 1995. 
MARCHEWKA, Tânia Maria N. "As contradições das medidas de segurança no contexto das ciências penais e da saúde mental: subsídio para o gestor de saúde". Monografia Final do I Curso de Especialização em Gestão de Serviços de Saúde Mental. Núcleo de Estudos de Saúde Pública (NESP) e Centro de Estudos Avançados Multidisciplinares (CEAM). Universidade de Brasília, 2001.

MARSIGLIA, Regina G. "Os cidadãos e os loucos no Brasil: a cidadania como processo". In: Saúde mental e cidadania. 2a ed. São Paulo: Mandacaru, 1987, pp. 13-28.

MINISTÉRIO DA SAÚDE. "II Conferência Nacional de Saúde Mental". Relatório Final. Brasília, 1993.

"Seminário Nacional sobre o direito à saúde mental - regulamentação e aplicação da Lei n. 10.216/2001". Brasília: Comissão de Direitos Humanos e Terceira Secretaria da Câmara dos Deputados/Ministério da Justiça/Ministério Público Federal/Conselho Nacional dos Procuradores-Gerais de Justiça/Organização Pan-Americana de Saúde (OPAS), 2001.

MOURA NETO, Francisco Drumond Marcondes de. "Bases para uma reforma psiquiátrica”. In: Saúde mental e cidadania. $2^{\text {a }}$ ed., São Paulo: Mandacaru, 1987, pp. 57-65.

NORONHA, E. Magalhães. "Direito penal”, 19a ed., São Paulo: Saraiva, 1981. v. 1.

PITTA, Ana Maria Fernandes; DALLARI, Sueli Gandolfi. "A cidadania dos doentes mentais no Sistema de Saúde do Brasil". Saúde em Debate, Londrina, n. 36, pp. 19-23, out. 1992.

SARACENO, B. Reabilitação psicossocial: uma prática à espera de teoria? In: PITTA, A. M. F. (Org.), "Reabilitação psicossocial no Brasil", São Paulo: Hucitec, 1996, pp. 88-97. 